\begin{tabular}{lllll}
\hline Motrivivência & Ano XX, & No 30, P. 111-127 & Jun./2008 \\
\hline
\end{tabular}

\title{
Formação inicial em educação física e atuação na escola: a hora da verdade ${ }^{1}$
}

\author{
Initial training in physical education and \\ practice in school: a moment of truth
}

Bruno Dandolini Colombo
Ana Lúcia Cardoso

\begin{abstract}
Resumo Abstract
O estudo tem como objetivo verificar qual a visão/opinião dos egressos do curso de licenciatura em Educação Física da Unesc sobre a formação oferecida pelo curso. Esse questionamento busca oferecer reflexões sobre a formação de professores de Educação Física. Foi realizada uma pesquisa de campo em que os sujeitos da pesquisa foram onze egressos do Curso de Licenciatura em Educação Física da Unesc. Concluímos que na opinião dos egressos sua formação foi muito significante para a atuação enquanto professor. Porém, ressaltam que somente no cotidiano escolar
\end{abstract}

1 Licenciado em Educação Física pela UNESC. Contato: br_colombo@hotmail.com

2 Licenciado em Educação Física pela UNESC. Contato: br_colombo@hotmail.com

3 Mestre em Educação Física e professora do Curso de Licenciatura da UNESC-Cricúma, SC. Contato: anc@unesc.net. 
ganharam maturidade necessária para evoluírem enquanto professores.

Propõem que a grade curricular do curso seja revista, dando maior ênfase à relação escola-universidade e apontam a necessidade de formação continuada aos professores do curso de licenciatura em Educação Física da UNESC.

Palavras Chaves: Formação de professores; Egressos; Licenciatura em Educação Física.

\section{Introdução}

O presente artigo busca refletir sobre a formação de professores de Educação Física, destacando a relação Universidade e Escola. Nesse contexto, segundo Silva e Pires (2006 p. 11):

As universidades, consideradas interlocutores privilegiados nos processos de capacitação de professores, devem priorizar a realização de programas institucionais de formação, com o objetivo de consolidar relações mais duradouras que gerem possibilidades de pesquisas com- maturity to develop themselves as teachers. They propose that curriculum is reviewed, and that it emphasizes school-university relationship. They also mention the necessity of continuous formation to professors of licentiate course in Physical Education of UNESC.

Keywords: Teacher's formation; Graduated students; Physical Education degree.

partilhadas sobre a intervenção, pautada na realidade concreta das escolas, e tendo o professor da escola como parceiro do processo. Acredita-se que tal procedimento poderá ainda influenciar positivamente na formação inicial de professores de Educação Física.

$\mathrm{O}$ interesse pelo assunto surgiu com a constatação do limitado acompanhamento dos egressos do Curso $^{4}$ de Licenciatura em Educação Física da UNESC na nova matriz curricular $\left(n^{\circ} 8^{5}\right)$. A matriz curricular do curso sofreu várias mudanças no decorrer dos anos e

4 Usaremos neste texto egresso como sinônimo de graduado e ou formado na instituição.

5 O referido curso passou por uma reforma da matriz curricular, na qual foi implantada em 2004, passando da matriz curricular $\mathrm{n}^{\circ} 6$ (que formava profissionais para atuar em todas as áreas da educação física) para a matriz $\mathrm{n}^{\circ} 8$, habilitando para a licenciatura, formando docentes para trabalhar com educação física escolar. Cabe ressaltar que também foi criado o curso de bacharel em Educação Física (matriz $\mathrm{n}^{\circ}$ 1), habilitando profissionais para atuar em todos os locais onde é praticada atividade física, menos na escola. Tais mudanças ocorreram para atender as diretrizes curriculares nacionais para a formação de professores de educação básica e do bacharel em Educação Física. 
há necessidade de conhecimentos sobre a eficiência das mesmas na formação dos profissionais.

Nota-se que atualmente já há uma escassez de professores no Brasil, devido à falta de estímulos nos aspectos financeiros e prestígio profissional. Conforme pesquisa da Confederação Nacional dos Trabalhadores em Educação (CNTE) realizada em 2003, 53,1\% dos professores em atividade estavam na faixa dos 40 aos 59 anos, e 38,4 \% tinham entre 25 e 39 anos. Apenas $2,9 \%$ encontravam-se na categoria entre os 18 e 24 anos. (FOLHA DE SÃO PAULO, 2005 apud TAFFAREL et al, 2007).

Com isso, compreendemos que seria uma possibilidade de esclarecimento "ouvir" a opinião dos "recentes" profissionais licenciados em Educação Física para esclarecer sobre tais aspectos e encaminhar algumas sugestões.

É inegável a importância de pesquisas que investiguem a formação profissional, pois permitem reflexões que encaminhe possibilidades de direcionamentos e mudanças nas matrizes curriculares dos cursos. As agências formadoras de profissionais devem fazer uma reflexão sobre e a partir dos profissionais que formou e sua inserção profissional na sociedade.

Portanto, o estudo teve como objetivo geral verificar qual a visão/opinião dos egressos do Curso de Licenciatura em Educação Física da Unesc sobre a formação oferecida pelo curso.

Para nortear futuras ações de melhoria e mudanças na matriz curricular e, consequentemente na formação profissional, justifica-se a importância de buscar a opinião dos egressos acerca de sua formação profissional a partir do contato direto com o campo de atuação profissional.

Conseqüentemente com tal aperfeiçoamento, professores mais preparados "surgirão" e, com isso, um ensino mais qualificado será construído junto à eles. Dessa forma, todos ganham o curso, os professores, os alunos, enfim, toda a sociedade.

Foi buscando esse aperfeiçoamento nas relações que optamos pela pesquisa de campo, sendo que esta, de acordo com Minayo (2003) possibilita ao pesquisador uma maior proximidade com o tema a ser estudado, permitindo uma melhor realização da pesquisa proposta. Sendo assim, possibilita também uma compreensão com maior relevância das diversas realidades existentes no cotidiano social, permitindo ao pesquisador um enorme leque de procedimentos e descobertas.

Os dados coletados foram analisados de forma qualitativa e quantitativa. Para Meksenas (2002, p. 130): "O caráter qualitativo do depoimento conduz o pesquisador 
ao trato com as concepções de mundo, os valores e as narrativas dos sujeitos investigados, capazes de explicar aspectos de suas práticas e das interações sociais passadas ou presentes".

A escolha dos indivíduos foi feita aleatoriamente. Numa pesquisa qualitativa é o individuo que é considerado como representativo pelo fato do mesmo ser o detentor de uma imagem particular da cultura á qual pertence. Sendo assim, as experiências sociais desse indivíduo são levadas em conta. Esse tipo de pesquisa procura selecionar um pequeno número de pessoas, escoIhidas em função de critérios que nada têm de probabilistas.

Aprofundando essa discussão, de acordo com Michelat (apud MEKSENAS, 2002), numa pesquisa quantitativa é a amostra que é considerada como representativa, considerando os valores estatísticos como determinantes. A escolha dos indivíduos é feita por acaso, sem levar em conta as particularidades dos mesmos, em relação as suas experiências sociais. Numa pesquisa qualitativa é o individuo que é considerado como representativo pelo fato do mesmo ser o detentor de uma imagem particular da cultura á qual pertence. Sendo assim, as experiências sociais desse indivíduo são levadas em conta. Esse tipo de pesquisa procura selecionar um pequeno número de pessoas, escoIhidas em função de critérios que nada têm de probabilistas.

Minayo (2003, p. 21) ressalta que:

\begin{abstract}
A pesquisa qualitativa responde a questões muito particulares. Ela se preocupa, nas ciências sociais, com um nível de realidade que não pode ser quantificado. Ou seja, ela trabalha com o universo de significados, motivos, aspirações, crenças, valores e atitudes, o que corresponde a um espaço mais profundo das relações, dos processos e dos fenômenos que não podem ser reduzidos á operacionalizações de variáveis.
\end{abstract}

A mesma autora (1994, p. 22) salienta que "o conjunto de dados quantitativos e qualitativos, porém, não se opõem. Ao contrário, se complementam, pois a realidade abrangida por eles interage dinamicamente, excluindo qualquer dicotomia".

A pesquisa de campo foi realizada, tendo como instrumento de coleta de dados o questionário, composto por 15 perguntas. Desde já ressaltamos que não será possível neste artigo elucidarmos toda pesquisa em si, portanto destacamos, num segundo momento, as que achamos mais importantes na busca 
da resposta desejada para a seguinte pergunta: Qual a visão/opinião dos egressos do Curso de Licenciatura em Educação Física da Unesc sobre a formação oferecida pelo curso.

Portanto, fizeram parte da pesquisa os egressos formados pela matriz curricular número 8 do Curso de Licenciatura em Educação Física da UNESC que atuam com Educação Física na escola pública. Buscando coerência com os princípios de uma educação crítica que por definição desvela as contradições socioeconômicas do capital e compreendendo que a formação inicial deve necessariamente responder a esse conjunto de tensionamentos, optamos em verificar a Educação Física na escola pública.

A matriz curricular de número oito iniciou em março de 2004. No final do ano de 2007 formaram-se 31 acadêmicos; no final do primeiro semestre de 2008 formaram-se 17 acadêmicos e em final 2008/2 totalizaram 29 acadêmicos que se formaram na habilitação de licenciatura em Educação Física. Totalizando 77 egressos do curso de licenciatura em Educação Física habilitados na matriz curricular oito.

Os sujeitos pesquisados foram os egressos do curso de licenciatura em Educação Física da Unesc formados na matriz número oito, que atuam na área de formação e que trabalham na rede pública da AMESC (Associação dos Municípios do Extremo Sul Catarinense), AMREC (Associação dos Municípios da Região Carbonífera) e AMUREL (Associação dos Municípios da Região de Laguna). Esses foram os critérios adotados para a participação do referido estudo. Atualmente dos egressos que estão formados na área, 14 egressos não atuam no âmbito escolar, sendo que alguns estão desempregados, outros atuam como: representante comercial, área de informática, vendas e outros. Dos egressos que a atuam no âmbito escolar dois atuam na educação especial (APAE) e cinco atuam na educação particular.

\section{A formação de professores: a opinião dos egressos}

Como já foi mencionado, não será possível elucidar no determinado artigo toda a pesquisa com as respectivas perguntas e respostas, porém evidenciamos as que encontramos de mais relevante para reflexões necessárias no que tange a formação de professores.

Dando continuidade, destacamos que dos 77 egressos do curso de licenciatura em Educação Física habilitados na matriz curricular oito, participaram da pesquisa onze egres$\operatorname{sos}(14,28 \%)$, sendo que sete são do sexo feminino $(63,63 \%)$ e quatro do sexo masculino $(36,36 \%)$. 
Dos onze egressos participantes da pesquisa, quando indagados sobre a pós-graduação, verificamos que: apenas dois possuem especialização (18.18\%); sete estão cursando especialização (63.63\%) e dois não possuem e nem estão fazendo especialização (18.18\%). Nenhum dos egressos possui ou está cursando mestrado. Mas o fato de já estarem cursando uma especialização é um indicativo positivo em relação a formação continuada.

Constatamos a preocupação dos egressos em uma formação continuada, sendo esta depois da graduação (formação inicial), com o intuito de capacitá-los para o mercado de trabalho e ampliar seus conhecimentos referentes à Educação Física. Lembrando que a formação inicial, segundo Sadi (2006) consiste na formação desenvolvida durante o processo de graduação. A formação continuada, por sua vez, é considerada o período posterior a essa formação inicial.

Quando abordados sobre quais as principais contribuições do Curso de Licenciatura em Educação Física da Unesc na formação acadêmica dos egressos, constatamos que os estágios supervisionados e a aprendizagem de como planejar e estruturar as aulas, destacam-se como as contribuições mais importantes para a formação acadêmica dos respectivos egressos, sendo ci- tadas em quatro oportunidades. Este fato é expresso por um dos egressos, que aponta: "ter o conhecimento de como planejar uma aula e os estágios foram muito importante para se ter uma vivência do que iria se enfrentar no futuro profissional".

Concluímos que essas questões referentes aos estágios supervisionados e ao planejamento e estruturação das aulas, estão mais ligadas à prática do que a teoria, ou seja, a preocupação principal dos acadêmicos está centrada no aprendizado da vivência do "ser professor", diretamente vinculada aos problemas que os professores enfrentam frente às realidades escolares.

Este fato encontra sintonia com as idéias de Tardif (2007) quando ressalta que a formação disciplinar e a formação cultural devem estar diretamente ligadas à formação prática. Acrescenta que durante o processo de formação inicial devem ser concebidos espaços para a formação prática no âmbito escolar: estágios de longa duração, contatos freqüentes com as escolas, análise das práticas e de casos específicos, entre outros. Todo esse processo significa melhor integrar os docentes da profissão no próprio currículo da formação inicial para o ensino, tornando estes verdadeiros atores sociais na formação dos futuros professores. Portanto, os professores de profissão não seriam 
meros participantes, mais sim participantes atuantes nesse processo de formação.

O pensamento crítico; a aprendizagem das teorias críticas; a crítica a visão esportivizada e a transformação social foram itens mencionados como contribuição do Curso de Licenciatura em Educação Física da Unesc. Ressaltamos que estas questões são tratadas pelo curso com muita propriedade, pois constam como um dos objetivos específicos do mesmo, no qual busca: viabilizar ações que envolvam a criticidade buscando sujeitos atuantes e comprometidos com a sociedade, capazes de exercerem plenamente o papel de cidadão/profissional de educação física, por meio da compreensão e da transformação das relações de poder. (PROJETO POLÍTICO PEDAGÓGICO, 2006). Podemos constatar com a pesquisa que, de certa forma, o curso viabilizou ações que envolvam criticidade, em vários aspectos, aos egressos, cabendo a esses a manutenção, enquanto cidadão, da luta por um mundo melhor.

Bracht (apud PROJETO POLÍTICO PEDAGÓGICO, 2006, p.11), afirma que "uma teoria crítica tem como categoria central a crítica do papel da educação na sociedade capitalista".

Quando perguntamos sobre as principais dificuldades encontradas pelos egressos, durante o curso de Licenciatura em Educação Física da Unesc, evidenciamos que: cinco egressos enfatizam como principal dificuldade o não comprometimento de alguns professores com o ensino dos conteúdos de suas respectivas disciplinas. Sendo assim um egresso ressalta que: "alguns professores agiam com descaso, muitas vezes não levando a sério o ensino de sua disciplina, o que acabava nos desmotivando".

Verificamos que além da preocupação na formação do professor de Educação Física na escola, a Universidade (Unesc) deve se preocupar também com a melhoraria da capacidade de alguns professores e o comprometimento destes com o ensino de suas disciplina ${ }^{6}$.

Aprender a ser crítico da realidade social e a atuação nos estágios apareceram em três oportunidades nas respostas dos egressos como dificuldades encontradas durante o curso. Consta que uma das dificuldades foi "a apropriação do conhecimento de forma crítica. Tendo em consideração que en-

6 Esta questão foi pesquisada no semestre de 2008/2 no Trabalho de conclusão de curso de Silva (2008) que concluiu que os professores do curso de licenciatura demonstraram uma limitação acerca do conhecimento das tendências pedagógicas em Educação Física. 
tramos no curso culturalmente e historicamente produzidos por uma sociedade que entende a Educação Física como disciplina voltada para o esporte técnico e de rendimento.".

Nessa perspectiva de aprender a ser crítico destacamos os estudo de Kunz (1991), no qual ressalta que devemos ter a capacidade de agir de maneira critica, ou seja, compreender o que está à nossa volta e argumentando sobre, tornando-se capaz de tomar decisões próprias, sem depender de outras pessoas.

Precisamos tornar ciência que "o ensino escolar necessita, [...], se basear numa concepção crítica, pois é pelo questionamento crítico que se chega a compreender a estrutura autoritária dos processos institucionalizados da sociedade e que formam [...] os falsos interesses e desejos." (KUNZ, 1991, p. 122).

Outra questão que consideramos relevante consiste nas disciplinas e conteúdos oferecidos pelo curso, se estes contribuíram para sua atuação como professor de Educação Física na Escola Pública. Pedíamos para que respondessem sim ou não e justificassem suas respostas, além de abordarem quais conteúdos e disciplinas contribuíram.

Dos onze pesquisados, nove responderam $\operatorname{sim}(81.81 \%)$; um não $(9.09 \%)$ e outro assinalou ambas as opções $(9.09 \%)$.
Os que responderam sim justificaram suas escolhas ressaltando que os conteúdos e disciplinas oferecidas pelo curso contribuíram principalmente na preparação do professor para a atuação e no saber relacionar a teoria com a prática.

Sobre quais disciplinas e conteúdos contribuíram mais para a atuação como professor de Educação Física na Escola Pública, os egressos elencaram as seguintes disciplinas: didática, que foi a mais mencionada, estando em seis respostas; estágios supervisionados apareceu em cinco respostas; Brincadeiras e Jogos; Metodologia dos Esportes Coletivos e Educação Infantil aparecem em três vezes cada; seguidos de Metodologia dos Esportes Individuais; Ensino Médio; e Aprendizagem e Desenvolvimento Motor, nas quais foram evidenciadas duas vezes de cada. Foram lembradas ainda: Educação Especial; Práticas Alternativas; Habilidade dos Esportes, Crescimento e Desenvolvimento Humano; Anatomia; Capoeira; Dança; e Recreação e Lazer.

Como vimos à disciplina de didática foi muito significativa para a maioria dos egressos. Em termos históricos ressaltamos que a didática nem sempre fez parte da grade curricular dos cursos de Educação Física. De acordo com (NETO et al, 2004) a formação do professor de Educação Física passou 
a ser enfatizada de maneira especial entre 1945 a 1968. Nesse período os cursos de Educação Física não exigiam a disciplina de didática, sendo que outros cursos de licenciatura exigiam tal disciplina.

Vimos um salto qualitativo na formação do professor de Educação Física sendo que a disciplina de didática, na qual enfatiza como ensinar, num certo momento histórico era considerada insignificante para a formação do mesmo. No momento atual, através da pesquisa, constatamos que esta passou a ser essencial para a formação do professor de Educação Física.

Verificamos também que as disciplinas pedagógicas, incluindo a didática, são enfatizadas como as que mais contribuíram para a formação dos egressos. Enquanto as relacionadas às áreas biológicas (como anatomia, cinesiologia, fisiologia, por exemplo) foram pouco mencionadas em relação a atuação no âmbito escolar. Isso evidencia que a matriz curricular vigente $\left(\mathrm{n}^{\circ}\right.$ 8) está atendendo, neste aspecto, os interesses de seus acadêmicos, em enfocar o ensino das disciplinas que estão diretamente ligadas a formação da prática pedagógica em Educação Física, como didática, estágio supervisionado, metodologia dos esportes coletivos, etc. Portanto, os ajustes feitos relacionados a matriz curricular anterior $\left(n^{\circ} 6\right)$, referentes a diminuição dos créditos das disciplinas das áreas biológicas, foram significativos para a melhoria do Curso de Licenciatura em Educação Física da Unesc.

Perguntamos também aos pesquisados se o curso propiciou discussão em relação aos aspectos de gênero, co-educação e inclusão. Oito responderam que sim $(72.72 \%)$; Três parcialmente $(27.27 \%)$ e nenhum optou pelo não. Dos que responderam sim, podemos destacar algumas falas dos referidos egressos, tais como: "sempre foi discutido, propiciado experiências sobre esses assuntos"; "a maioria das disciplinas sempre deu importância a esses aspectos"; "os professores [...] realizavam inúmeros debates, seminários, etc.".

Salientamos que estes aspectos foram mencionados por entendermos ser indispensáveis numa aula de Educação Física. Portanto, Para Kunz (apud SARAIVA, 2005, p. 173):

A Educação Física contribui para reforçar uma socialização específica em relação ao sexo [...]. Neste sentido, a Educação Física poderia ter a chance de sensibilizar para uma futura superação da contradição social em relação aos diferentes papeis assumidos pelo homem e pela mulher na sociedade, concentrando sua temática de 
movimentos e jogos na aprendizagem social co-educativa.

Porém, ainda são muito presentes nas aulas de Educação Física condutas que busquem a vitória no jogo, seja qual for este. Sendo assim o erro é encarado como um incômodo, principalmente por parte dos meninos, que julgam o erro das meninas de maneira agressiva. Numa aula de Educação Física também se pode exercer demonstrações de forças e gestos ameaçadores, afastando os indivíduos uns dos outros. (SARAIVA, 2005).

Para Saraiva (2005, p. 174) "Tais ações poderão ser abolidas no processo comunicativo, em beneficio da cooperação, solidariedade e efetiva participação de todos". Salienta que o diálogo no qual se trata a afirmativa acima só será possível, de maneira "igual" para todos, se oportunizarmos aulas co-educativas.

Em relação a participação de todos no âmbito escolar, outra questão vem em pauta. $\mathrm{O}$ tema da inclusão. Brevemente, ressaltamos que o termo inclusão na educação remete numa mudança no qual envolve um processo de reforma nas escolas, com o objetivo de garantir a participação e o acesso a todas as crianças, incluindo aquelas com deficiência. (MITTLER, 2003).

Para que isso ocorra é preciso que se conheçam todas as dificuldades possíveis de se evidenciar, para que se planeje um programa de intervenção objetivando a integração da criança no sistema educacional. (MITTLER, 2003).

A inclusão não parte do princípio de adaptação do aluno frente a escola, mas sim, numa reforma radical dessa instituição em termos de currículo, avaliação, pedagogia e formas de agrupamento dos alunos nas atividades intra-classe. Busca-se, com isso, o bem-estar de todos, celebrando a diversidade. (MITTLER, 2003).

Depois das reflexões acercas dos estudos teóricos expostas anteriormente, nos reportamos novamente a pesquisa, mais especificamente na pergunta referente ao curso, se este propiciou discussão em relação aos aspectos de gênero, co-educação e inclusão. Vimos que a maioria respondeu que sim. Ressaltamos, portanto, que o Estágio Supervisionado foi mencionado em três oportunidades, destacando a importância deste no desenvolvimento dos estudos relacionados aos respectivos aspectos. Resumi-se tal importância através da fala de um dos egressos, no qual ressalta que: "o estágio supervisionado foi de grande valia para o enriquecimento e a prática do conhecimento adquirido em sala de aula".

Sobre os egressos que assinalaram parcialmente, consta- 
tamos que todos acharam que as discussões e vivências sobre inclusão deveriam ser mais enfatizadas no curso. Sobre gênero, um pesquisado achou ser também pouco enfatizado. Já o terceiro aspecto, co-educação, todos concordam que foram bem vivenciados no curso.

Constatamos que o Curso, de uma forma geral, propiciou discussões referentes aos aspectos de gênero, co-educação e inclusão e que o estágio supervisionado foi uma maneira de colocar essas discussões em prática e ampliar as vivências oferecidas pelo curso.

Outra questão considerada por nós importante consiste na formação oferecida pelo curso, se esta foi suficiente para a atuação profissional na escola pública. Cinco egressos responderam sim $(45.45 \%)$ e seis não $(54.54 \%)$.

Os que responderam sim destacam em uma oportunidade cada, os ensinamentos: nos planejamentos de aulas; na (re)construção de materiais; nos conteúdos variados; referentes as críticas frente a realidade social na qual vivemos; das concepções pedagógicas; na educação infantil. Todos esses itens deram sustentação (base) a atuação profissional dos respectivos egressos. Os estágios ganham destaque novamente, sendo mencionados por dois egressos, pela importância de viver a realidade escolar, fazen- do com que os acadêmicos tenham certa experiência na sua atuação profissional.

Os seis egressos que responderam não, analisando suas falas, concordam que para ser professores em escola pública o que conta mais é enfrentar a realidade escolar, ganhando experiência no dia-a-dia. No entanto consideram importante a formação oferecida pelo curso, isso se torna evidente na fala de um dos egressos, na qual ressalta que a formação oferecida pelo curso: "ajudou, mas não foi suficiente, pois na escola a realidade é diferente, o dia-a-dia é complicado, mas isso vamos aprendendo com o tempo, quando ganhamos experiência".

As considerações anteriormente expostas se enquadram nas perspectivas defendidas por Tardif (2007) no qual defende uma maior aproximação dos acadêmicos com a realidade escolar, vivendo-a com maior intensidade. Sendo assim propõe soluções prévias como: estágios de longa duração, contatos freqüentes com as escolas, análise das práticas e de casos específicos, entre outros.

Uma aproximação com a realidade das escolas, traria maior experiência aos acadêmicos, com isso estariam mais preparados para enfrentarem os desafios quando fossem atuar como professores no âmbito escolar. 
Quando perguntados se o curso propiciou um posicionamento crítico frente a realidade social na qual vivemos, os egressos foram unânimes optando pela resposta $\operatorname{sim}(100 \%)$. Nas justificativas alguns pontos devem ser levantados, tais como: a visão crítica foi vinculada, em cinco oportunidades, à realidade escolar e aos empecilhos que se encontram nesse contexto. Em quatro respostas, a visão crítica foi abordada em sentido mais amplo (global). Isto pode ser conferido na resposta de um dos entrevistados, onde ressalta que: "passei a compreender as relações de força e interesse do sistema. Com isso pude tomar um posicionamento crítico a essas relações enquanto antes agia influenciado por esse mesmo sistema".

Ainda foi ressaltado que houve debates sobre esses aspectos de criticidade, buscado o suporte nos meios de comunicação. O estágio também foi citado como uma "vitrine" da realidade escolar.

A unanimidade nas respostas nos permite confirmar que o Curso de Licenciatura em Educação Física da Unesc realmente propiciou discussões relevantes no que concerne a realidade social na qual vivemos se aproximando de alguns objetivos na qual prioriza como a formação de um ser crítico que conheça a realidade a sua volta para poder intervir sobre ela, tendo a possibilidade de transformar a sociedade na qual está inserido. Indagados sobre quais as sugestões para o curso de Licenciatura em Educação Física da Unesc, verificamos que dez egressos, de alguma forma, questionaram a mudanças referentes a grade curricular. Dentre as dez respostas, três apontam para a melhoria dos estágios supervisionados (aumento de créditos e o acompanhamento dos professores na escola com maior intensidade).

Ainda sobre a grade (matriz) curricular, foram apontadas algumas sugestões: enfoque na educação infantil; Diminuir a carga de trabalho no ultimo semestre; Melhorar educação especial e psicologia; natação como optativa, já que na grande maioria das escolas não há piscina; criar uma disciplina focada na construção dos próprios materiais e na adaptação de atividades para espaços físicos relativamente pequenos; Aumento de créditos: Dança; Habilidades dos Esportes; Recreação e Lazer; e Jogos e Brincadeiras;

Através da fala de um dos egressos, podemos especificar o desejo dos egressos referente às expectativas da grade curricular: "que as grades das disciplinas sejam revistas, pois existem disciplinas que pouco utilizamos durante a nossa 
atuação e as mesmas possuem quatro créditos [...], já algumas que seriam muito melhor aproveitadas em nossa prática no dia a dia possuem somente duas [...]."

Tratando-se da melhoria da grade (matriz) curricular, fizemos um resgate na fundamentação teórica relativa à Proposição de Diretriz Curricular para a Formação de Professores de Educação Física de Taffarel et al. (2007) na qual propõe a multidisciplinaridade como fator relevante na formação profissional/acadêmica, assim como considera necessário a presença de campos de conhecimentos diferenciados no currículo, como: Ciências Biológicas/saúde; Ciências Humanas/Sociais, da Terra, das Ciências Exatas, Filosofia e Artes. A História é vista como ciência significante para Educação Física, pois é a partir dela que compreendemos tanto o passado e o presente quanto o futuro do ser humano.

Com isso, tal grupo é contrário à fragmentação das ciências, propondo como matriz científica para a formação de professores a história do homem e sua relação com a natureza, assim como, a relação entre os homens entre si e consigo mesmo.

Tratando sempre de termos históricos a Educação Física se caracteriza pelo trabalho pedagógico da docência no trato com o conhecimento da cultura corporal.
A docência é, portanto a identidade do professor de Educação Física.

Nesse contexto, Taffarel et al $(2007$, p. 46 - 47) ressalta que:

A consolidação da identidade do professor de Educação Física para o exercício profissional, durante a sua formação acadêmica, requer:

- sólida formação teórica de base multidisciplinar e interdisciplinar na perspectiva da formação omnilateral;

- unidade entre teoria e prática, [...], tomando o trabalho como princípio educativo e como práxis social;

- gestão democrática [...];

- compromisso social com ênfase na concepção históricosocial do trabalho [...];

- trabalho coletivo, solidário e interdisciplinar;

- formação continuada para permitir a relação entre formação inicial e continuada no mundo do trabalho;

- avaliação permanente como parte integrante das atividades curriculares $[\ldots]$

A Educação Física tem como objeto de estudo o fenômeno das práticas no qual se manifesta por meio de atividades que proporcionem relações múltiplas de experiências ideológicas, políticas, filosóficas e outras, vinculadas ás 
leis histórico-sociais. (TAFFAREL et al, 2007).

Os mesmos autores (2007, p. 48) salientam que "os currículos plenos para os cursos de Licenciatura Ampliada em Educação Física terão, portanto, a cultura corporal como objeto, a prática social (práxis) como eixo articulador do conhecimento e a História como matriz científica".

O mesmo grupo de autores ainda conclui ressaltando a significante compreensão da realidade a nossa volta, mediante aos interesses de classes, para que posamos intervir positivamente, aprofundando as relações com os movimentos de luta para que possamos avançar nas contribuições para a formação de professores de Educação Física na perspectiva de libertação humana das amarras impostas pela sociedade vigente.

Enfim, ao final deste estudo que investigou acerca da visão dos egressos do Curso de Licenciatura em Educação Física da UNESC em relação à formação oferecida pelo curso é inevitável resgatar o caminho trilhado. Inicialmente percorremos determinados caminhos, por meio de estudos teóricos. Na perspectiva de contribuição da qualidade na formação inicial de professores, destacamos os estudos de Tardif (2007), no qual enfatiza que os programas de formação dos professores (incluindo as universi- dades), deveriam passar por uma série de transformações significativas nas práticas atuais. Isso significa que estes devem ser organizados com base em um novo centro de gravidade: a formação científica (ou disciplinar) e a formação cultural (ou geral). Ambas não podem estar desvinculadas com a formação prática. Sendo assim, durante esse processo: devem ser concebidos espaços para a formação prática no âmbito escolar: estágios de longa duração, contatos freqüentes com as escolas, análise das práticas e de casos específicos, entre outros.

A pesquisa de campo indicou as principais contribuições e dificuldades oferecidas pelo curso em sua formação acadêmica em relação à atuação no âmbito escolar, destacamos que as principais contribuições foram relacionadas ao estágio supervisionado e ao planejamento da aula. Entendemos que estas questões estão mais vinculadas à prática do que a teoria, ou seja, a preocupação principal dos acadêmicos está centrada no aprendizado da vivência do "ser professor", diretamente vinculada aos problemas que os professores enfrentam frente à realidade escolar.

Quanto às dificuldades elucidamos que os egressos mostraram-se descontentes com a falta de comprometimento de alguns professores com o ensino dos conte- 
údos de suas respectivas disciplinas. Sendo assim, além de se preocupar com a formação do professor de Educação Física na escola, a universidade deve se preocupar ainda mais com a melhoraria da capacidade de alguns professores e o comprometimento destes com o ensino de suas disciplina, por meio de conversas diretas, seminários, ou até mesmo na busca de professores comprometidos com a qualidade de ensino em prol da formação do professor de Educação Física.

Constatamos que as disciplinas e os conteúdos ajudaram na atuação na escola. Destacaram a disciplina de didática como a que mais contribuiu para a atuação na escola. Em uma análise geral entendemos que o estágio supervisionado se apresentou como o mais relevante na vida dos egressos, justamente por aproximar a formação acadêmica com a realidade escolar.

Contudo constatamos também que mesmo com toda essa contribuição os egressos alegam não ser suficiente à formação oferecida pelo curso, por entenderem que ganharam experiência, na medida em que fizeram o enfrentamento com o cotidiano escolar.

A formação crítica frente à realidade social foi um aspecto em que todos os egressos foram unânimes. Confirmando que o Curso de Licenciatura em Edu- cação Física da Unesc realmente propiciou discussões relevantes no que concerne a realidade social na qual vivemos, se aproximando de alguns objetivos na qual prioriza, como a formação de um ser crítico que conheça a realidade á sua volta para poder intervir sobre ela, tendo a possibilidade de transformar a sociedade na qual está inserido.

As discussões referentes aos aspectos de gênero, co-educação e inclusão foram apontadas como temas que foram significativos em sua formação, e, sobretudo que o estágio supervisionado foi uma maneira de colocar essas discussões em prática e ampliar as vivências oferecidas pelo curso.

$\mathrm{Na}$ tentativa de sintetizar a conclusão deste estudo, destacamos que na opinião dos egressos a formação foi muito significante para sua atuação enquanto professor, porém ressaltam que somente no cotidiano escolar ganharão maturidade necessária para evoluírem enquanto professor. Entendem também que a grade curricular do curso deva ser revista, dando ênfase na relação escola e universidade e apontam à necessidade de formação continuada aos professores do curso de educação física da UNESC.

Com este estudo buscamos contribuir na contínua qualificação do curso de Educação Física da UNESC, com o intuito de 
formarmos professores e cidadãos preparados para enfrentar a realidade social, na busca sempre de um mundo mais justo e igualitário.

\section{Referências}

COLOMBO, Bruno Dandolini. Formação Inicial em Educação Física e Atuação na Escola: A Hora da Verdade. 2009. 69 p. TCC (Graduado em Licenciatura em Educação Física). Universidade do Extremo Sul Catarinense. Criciúma.

KUNZ, Elenor. Transformação Didático-Pedagógica do Esporte. ljuí: Unijuí. 1991

MEKSENAS, Paulo. Pesquisa social e ação pedagógica: conceitos, métodos e práticas. São Paulo: Loyola. 2002.

MINAYO (org), Maria Cecília de Souza. Pesquisa social: teoria, método e criatividade. 22. ed. Petrópolis: Vozes. 2003.

MITTLER, Peter J. Educação Inclusiva: contextos sociais. Porto Alegre: Artmed, 2003. 264 p.

NETO, Samuel de Souza et al. A formação do profissional de educação física no Brasil: Uma história sob a perspectiva da legislação federal no século XX. Revista brasileira de ciências do esporte, Campinas, v. 25, n. 2, p. 113 - 128, janeiro. 2004.
PROJETOPOLÍTICOPEDAGÓGICO. Curso de Licenciatura em Educação Física da UNESC. Criciúma, 2006. $51 \mathrm{p}$.

ROSA, Mariana da Silva. A Educação

Física da Unesc: um diálogo com os professores. 2008. 45 p. TCC (Graduada em Licenciatura em Educação Física). Universidade do Extremo Sul Catarinense. Criciúma.

SADI, Renato Sampaio. Formação Permanente de Professores de Educação Física: notas de investigação sobre o conhecimento crítico-criativo. Motrivivência, Florianópolis, ano XVIII, n. 26, p. $47-68$, junho. 2006.

SARAIVA, Maria do Carmo. Coeducação física e esportes quando a diferença é mito. 2 . ed. ljuí: Unijuí, 2005.

SILVA, Maurício Roberto; PIRES, Giovani De Lorenzi. Formação Inicial e Capacitação continuada em serviço de professores de educação física: duas faces do mesmo desafio. Motrivivência, Florianópolis, ano XVIII, n. 26, p. 09 - 14, junho. 2006.

TAFFAREL, Celi Zülke et al. Uma Proposição de Diretriz Curricular para a Formação de Professores de Educação Básica. In: TAFFAREL, Celi Zülke; HILDEBRANDTSTRAMANN, Reiner (Org). Currículo e Educação Física: 
Formação de professores e práticas pedagógicas nas escolas. Ijuí: Unijuí, 2007. 470 p. (Coleção Educação Física)

TAFFAREL, Celi Zülke et al. Reestruturação Curricular do Curso de Licenciatura em Educação Física da UFBA: contribuições dos professores da Rede Pública de Ensino do Estado da Bahia. In: TAFFAREL, Celi Zülke; HILDEBRANDTSTRAMANN, Reiner (Org).
Currículo e Educação Física: Formação de professores e práticas pedagógicas nas escolas. Ijuí: Unijuí, 2007. 470 p. (Coleção Educação Física) TARDIF, Maurice Tardif. Saberes Docentes e Formação Profissional. 8. ed. Petrópolis: Vozes. 2007. 325 p.

Recebido: 30/agosto/2009 Aprovado: 19/outubro/2009 